\title{
Yellow mud/gel composites for preventing coal spontaneous combustion
}

\author{
Yinghua Zhang ${ }^{1, a}$, Peiling Zhou ${ }^{1, b}$, Zhi'an Huang ${ }^{1, c}$, Yukun ${ }^{1, d}$ Gao and \\ Liwen Jiang ${ }^{1, e}$
}

${ }^{1}$ State Key Laboratory of High-Efficient Mining and Safety of Metal Mines (University of Science and Technology Beijing), Ministry of Education, Beijing 100083, P. R. China.

azyhustb@163.com, ${ }^{b}$ pellyzhou@163.com, chuang_za@qq.com, ${ }^{\mathrm{d}}$ gaoyukunustb@126.com, ${ }^{\mathrm{e} j \mathrm{j} \text { w03 }}$ 2333@yeah.net

Keywords: spontaneous combustion of coal, gel composites, best proportion.

\begin{abstract}
To address the shortcomings of single use of existing fire prevention materials, a novel composite that combined the characteristics of yellow mud and gel was designed and investigated. The composite grout composed of yellow mud and polymer gel can overcome the limitations of single fire prevention materials in fire preventing and extinguishing, and had excellent fluidity and targeting. In view of initial setting time, viscosity, gelling time, material dosage et al., based on the characteristics of the solid-liquid two-state, using the experiments and linear regression methods, the relationship between the different components and its performance were researched, and best raw material components and ratio were chosen. As effective materials for preventing spontaneous combustion of residual coal in goaf, the composites with a water-to-soil ratio of 4:1, base material (4\%), coagulant (5\%) and polymer materials $(0.75 \%$ ) had advantages of good liquidity, complete coverage, short gelling time and non-pollution.
\end{abstract}

\section{Introduction}

The energy structure in China is that oil reserves is less than coal reserves, and coal consumption accounts for more than $70 \%$ of China's primary energy consumption[1,2]. According to statistics, fires that caused by spontaneous combustion represents more than $90 \%$ of the fire disasters. As a result, the loss amount of high quality coal has reached more than 4.2 billion tons, and is still increasing [3].

The main reason of coal spontaneous combustion is that oxidation reaction of coal and oxygen, which generate a lot of heat. The heat aggregation will cause the gradual heating up of coal. When temperature reaches the ignition point of coal, spontaneous combustion will be caused $[4,5,6]$. According to the law of reaction between coal and oxygen, oxidation reaction will occur as long as coal and oxygen contact, and the higher concentration of oxygen the faster speed of reaction, so through isolating coal and oxygen by plugging, oxidation rate can be reduced [7]. At the same times, the reaction rate increases with the increasing temperature, thus reducing the coal temperature can make coal oxidation rate decrease too [8].

Although there are many fire prevention materials, they all have many drawbacks. pouring the yellow mud cannot cover the coal body evenly, which has no effect on the float coal in middle and high places, and the amount of dehydration is large, so it is not suitable for long-term use [9]; retarder can easily corrode the equipment, and the inhibitive effects are affected by the lifetime of retarder; inert gas will spread if there is air leakage, and it is difficult to remain in the injected area; the cost of gel is high, the flow is small, it is only suitable for local fire district [10].

\section{Mechanism of yellow mud adding gel materials to prevent coal spontaneous combustion}

Mechanism of coal spontaneous combustion. Spontaneous combustion of coal is the result that exothermic rate of oxidation is greater than heat dissipation rate to the surrounding environment. 
According to the Arrhenius law and the mass action law, exothermic heat per unit time of the high temperature coal is: $Q_{1}=k_{0} C^{n} \exp \left(-\frac{E}{R T}\right) V q$

where $\mathrm{V}$ is the volume, $\mathrm{K}_{0}$ is a constant related to coal structure, $\mathrm{C}$ is the concentration of reactant in combustible mixture (according to the theory of coal and oxygen reaction, it refers to the oxygen concentration on surface active points of coal, and it is associated with the nature and the specific surface area of coal), $\mathrm{n}$ is the reaction series, $\mathrm{V}$ is the volume of high temperature coal, $\mathrm{q}$ is the combustible mixture heat of reaction, and $k_{0} C^{n} \exp \left(-\frac{E}{R T}\right)$ is the reaction rate constant.

For certain high temperature range, the temperature is set to be $T$, environment temperature is $T_{0}$, the contact area between high temperature area and surrounding coal is S. The heat dissipating capacity as follows: $Q_{2}=\lambda S\left(T-T_{0}\right)$

Thermal conductivity $\lambda$ and heat dissipation area $S$ all have influence on heat dissipating capacity. Heat dissipating capacity and heat dissipation rate are directly proportional to that thermal conductivity, heat dissipation area, the temperature difference between coal and environmental.

$$
\frac{d Q_{1}}{d T}=\frac{d Q_{2}}{d T}
$$

Therefore, in order to effectively prevent coal spontaneous combustion, isolating oxidation, improving thermal conductivity, and increasing heat dissipation area can enhance heat dissipating capacity of coal body and lower temperature of the environment.

Mechanism of gel composite preventing spontaneous combustion. The yellow mud adding gel material is composite gel originated from the chemical reaction between yellow mud, base material of gel and coagulant.

(1) Wetting and conjunctival closing

Both raw materials of the inorganic gel before gelling and organic solution of colloidal gel material have the properties of liquidity. The material can wet coal, namely after the media contact them, surface free enthalpy can be reduced.

(2) Changing heat conduction performance

According to the Fourier law of heat conduction, basic equation of thermal conductivity on composite materials in the unsteady can be expressed as follows: $\frac{\partial^{2} T}{\partial^{2} X}=\frac{1}{\alpha} \frac{\partial T}{\partial t}+\frac{q^{\prime \prime}}{k}$

In the formula, $\alpha$ is the thermal diffusivity, and $q^{\prime \prime}$ is the heat release rate per unit volume. Gel composite heat conduction performance and thermal conductivity $\lambda$, specific heat ${ }^{C_{p}}$ and density $\rho$ are closely related to that: $\frac{\Delta T}{\Delta t}=\frac{\lambda}{c_{p} \rho} \Delta^{2} T$

Because coal is porous media, composite particles fill in it, according to the Maxwell formula:

$$
\lambda_{c}=\lambda_{m} \frac{\lambda_{r}+2 \lambda_{m}-2 V_{r}\left(\lambda_{m}-\lambda_{r}\right)}{\lambda_{r}+2 \lambda_{m}+V_{r}\left(\lambda_{m}-\lambda_{r}\right)}
$$

In summary, when composite gel is injected on the coal, it wet the coal and a layer of insoluble membrane forms, which reduces surface oxygen concentration, increase heat dissipation area, thermal conductivity and specific heat capacity. Therefore, heat release amount is reduced, but heat dissipating capacity is increased, achieving the purpose of spontaneous combustion prevention. In the macroscopic, influence factors include viscosity of the gel, gelling time and gelling mass.

\section{Experimental materials and methods}

The effects of different raw materials on viscosity of gel, gelling time and gelling mass, were investigated systematically using the single factor variable method. 
Through orthogonal experiments and range analysis, the initial setting time of different materials, different ratio of raw materials, and gelling time were analyzed respectively to optimize the ratio of the composites to prevent spontaneous combustion.

\section{Results and discussion}

Effects of different coagulant on the gelling mass. As regard to sodium aluminate and sodium bicarbonate, various concentration of cross-over experiments were conducted and the gelling mass under the same reaction quality were compared.

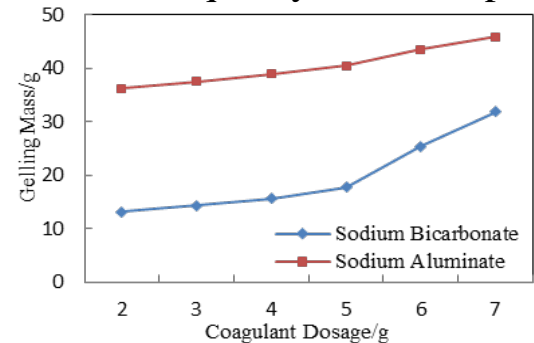

(a) Diagram of the base material dosage is $2 \mathrm{~g}$

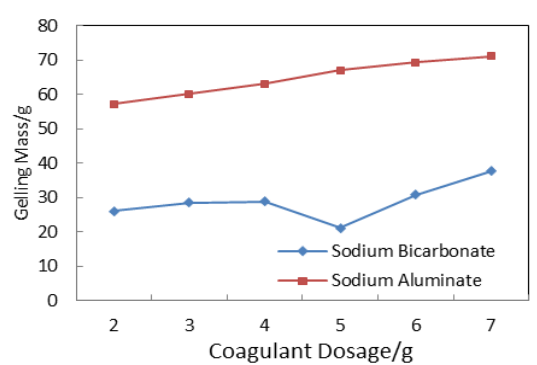

(c) Diagram of the base material dosage is $4 \mathrm{~g}$

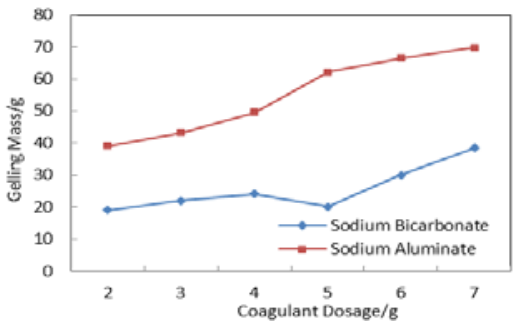

(b) Diagram of the base material dosage is $3 \mathrm{~g}$

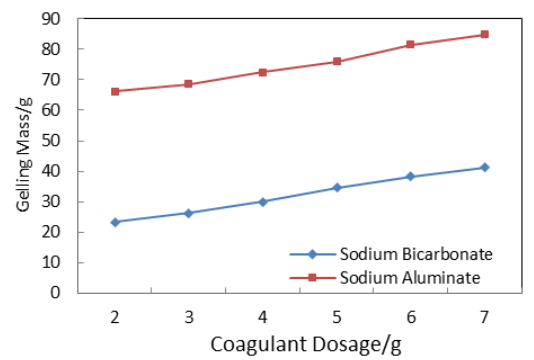

(d) Diagram of the base material dosage is $5 \mathrm{~g}$

Fig.1 The relationship between coagulant and gelling mass under the different base material dosage

Fig.1 (a) (b) (c) (d) represent the relationship between coagulant and gelling mass, when the dosage for base material is $2 \mathrm{~g}, 3 \mathrm{~g}, 4 \mathrm{~g}$ and $5 \mathrm{~g}$, respectively. As seen in the Fig.3, when reactions with the same initial mass of base material and coagulant, sodium aluminate as coagulant generated more colloid, when compared with sodium bicarbonate. Meanwhile, the more the coagulant is, the better the quality of colloid is. However, the following phenomena should be taken into consideration during the experiment:

(1) Sodium aluminate is corrosive and downhole equipment will be corrosion if long-term use.

(2) Found by calculating, the cost of sodium aluminate required is nearly equal to sodium bicarbonate when the same quality colloid is generated.

(3) Sodium bicarbonate dissolution process is an endothermic process, while sodium aluminate dissolution process is exothermic. As coagulant, sodium bicarbonate plays the better role to endothermic and cooling. Considering the above-mentioned problems and its characteristics of resistance, sodium bicarbonate is selected as coagulant.

Relationship between ratio of raw materials and gelling time. Different concentration of base material and coagulant dosage has an important influence on the initial setting time and gelling time. Through cross experiments, relationship between coagulant dosage and gelling time under different base material dosage was analyzed, as shown in Fig.2 and Fig.3, the curves indicate that:

(1) When the base material dosage is $C_{A}$, the relations between coagulant dosage and gelling time conforms to the following equation: $t=a C_{B}{ }^{-b}$, where $C_{B}$ is coagulant dosage, $t$ is the initial setting time, and $\mathrm{a}, \mathrm{b}$ are coefficients. The values of $\mathrm{a} b$ are shown in the Table 1 .

(2) When the coagulant concentration is $2 \%$ to $5 \%$, it has a large effect on the gelling time.

Above $5 \%$, this effect can be neglect, and below $2 \%$, the gelling time is $78 \mathrm{~min}$.

Considering that the gelling time should be between 1 to $30 \mathrm{~min}$, the coagulant concentration should be between $3 \%$ to $5 \%$.

(3) When base material dosage is between $2 \%$ to $4 \%$, there is a larger impact on gelling time. 


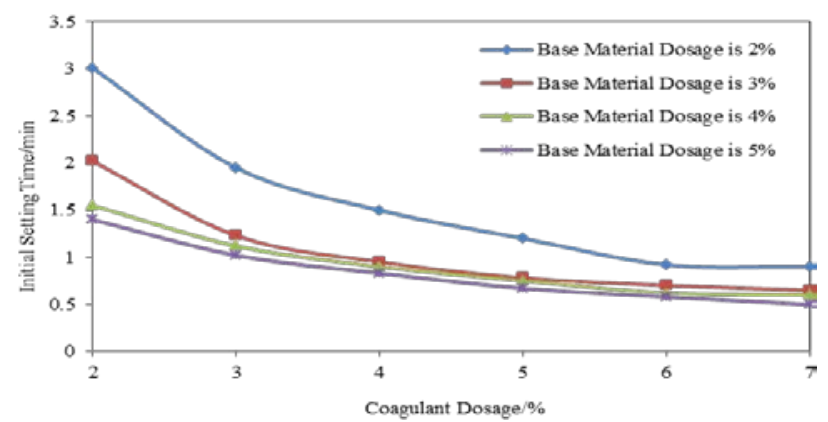

Fig.2 Curves of relationship between proportion of gel material and initial setting time

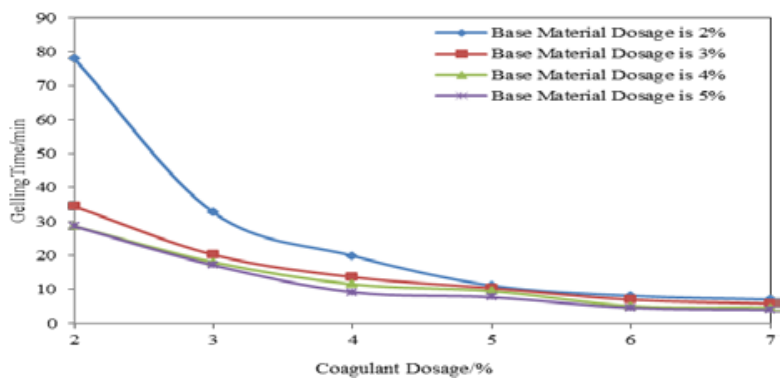

Fig.3 Curves of relationship between proportion of gel material and gelation time

Table 1 The regression equation coefficient table

\begin{tabular}{c|c|c|c|c}
\hline \multirow{2}{*}{$\begin{array}{c}\text { Base Material } \\
\text { Dosage }\end{array}$} & \multicolumn{2}{|c|}{$\begin{array}{c}\text { Equation coefficients of material ratio and } \\
\text { initial setting time }\end{array}$} & $\begin{array}{c}\text { Equation coefficients of material ratio } \\
\text { and gelling time }\end{array}$ \\
\cline { 2 - 5 } & $\mathrm{a}$ & $\mathrm{b}$ & $\mathrm{a}$ & $\mathrm{b}$ \\
\hline $2 \%$ & 3.09 & 0.71 & 81.86 & 1.39 \\
\hline $3 \%$ & 1.96 & 0.64 & 37.59 & 0.99 \\
\hline $4 \%$ & 1.59 & 0.55 & 32.89 & 1.04 \\
\hline $5 \%$ & 4.65 & 0.57 & 32.12 & 1.10 \\
\hline
\end{tabular}

Effects of polymer additives on the gel mobility. The gel formed by the chemical reaction is Newtonian fluid, whose viscosity is small. Adding polymer into the raw materials can slow down the flow velocity and increase the viscosity. Adjusting the flow rate can improve gel coverage rate.

Table 2 Experimental data when mass ratio of base material and coagulant is 2:3

\begin{tabular}{|c|c|c|c|c|}
\hline $\begin{array}{l}\text { Initial setting time of inorganic gel } \\
\text { /min }\end{array}$ & 1.95 & \multirow{2}{*}{$\begin{array}{l}\text { Initial setting } \\
\text { time /min }\end{array}$} & \multirow{2}{*}{$\begin{array}{l}\text { Gelling time } \\
\text { /min }\end{array}$} & \multirow{2}{*}{$\begin{array}{c}\text { Inorganic polymer } \\
\text { blend viscosity } / \mathrm{mPa} \bullet \mathrm{s}\end{array}$} \\
\hline $\begin{array}{l}\text { Gelation time of inorganic gel } \\
(\min )\end{array}$ & 32.67 & & & \\
\hline \multicolumn{2}{|c|}{ Mass fraction of polyacrylic acid sodium is $0.5 \%$} & 1.83 & 32.47 & 1.31 \\
\hline \multicolumn{2}{|c|}{ Mass fraction of polyacrylamide is $0.5 \%$} & 1.68 & 30.45 & 1.28 \\
\hline \multicolumn{2}{|c|}{ Mass fraction of polyacrylic acid sodium is $1 \%$} & 1.48 & 28.67 & 34.3 \\
\hline \multicolumn{2}{|c|}{ Mass fraction of polyacrylamide is $1 \%$} & 1.42 & 27.23 & 3.1 \\
\hline
\end{tabular}

Table 3 Experimental data when mass ratio of base material and coagulant is 2:4

\begin{tabular}{|c|c|c|c|c|}
\hline $\begin{array}{l}\text { Initial setting time of inorganic } \\
\text { gel /min }\end{array}$ & 1.5 & \multirow{2}{*}{$\begin{array}{l}\text { initial setting } \\
\text { time } / \mathrm{min}\end{array}$} & \multirow{2}{*}{$\begin{array}{l}\text { Gelling time } \\
\text { /min }\end{array}$} & \multirow{2}{*}{$\begin{array}{c}\text { Inorganic polymer } \\
\text { blend viscosity } \\
\text { /mPa•s }\end{array}$} \\
\hline $\begin{array}{l}\text { Gelation Time of Inorganic Gel } \\
\text { /min }\end{array}$ & 19.89 & & & \\
\hline \multicolumn{2}{|c|}{$\begin{array}{l}\text { Mass fraction of polyacrylic acid sodium is } \\
0.5 \% \text { o }\end{array}$} & 1.4 & 15.5 & 1.6 \\
\hline \multicolumn{2}{|c|}{ Mass fraction of polyacrylamide $0.5 \%$} & 1.32 & 14.8 & 1.25 \\
\hline \multicolumn{2}{|c|}{ Mass fraction of polyacrylic acid sodium is $1 \%$} & 1.28 & 12.82 & 23.35 \\
\hline \multicolumn{2}{|c|}{ Mass fraction of polyacrylamide is $1 \%$} & 1.07 & 13.68 & 3.05 \\
\hline
\end{tabular}


Table 4 Experimental data when mass ratio of base material and coagulant is 2:5

\begin{tabular}{c|c|c|c|c}
\hline $\begin{array}{c}\text { Initial setting time of inorganic } \\
\text { gel /min }\end{array}$ & 1.2 & $\begin{array}{c}\text { Initial setting } \\
\text { time /min } \\
\text { Gelation time of inorganic } \\
\text { gel/min }\end{array}$ & $\begin{array}{c}\text { Gelling time } \\
\text { /min }\end{array}$ & $\begin{array}{c}\text { Inorganic polymer } \\
\text { blend viscosity /mPa•s }\end{array}$ \\
\hline $\begin{array}{c}\text { Mass fraction of polyacrylic acid sodium is } \\
0.5 \% \text { on }\end{array}$ & 1.22 & 8.85 & 1.25 \\
\hline Mass fraction of polyacrylamide is 0.5\%o & 1.03 & 7.78 & 1.02 \\
\hline Mass fraction of polyacrylic acid sodium is 1\%o & 0.92 & 8.47. & 37.8 \\
\hline Mass fraction of polyacrylamide is 1\%o & 0.87 & 6.48 & 3.46 \\
\hline
\end{tabular}

Table 2, 3 and 4 show the relationship between polymer materials, sodium polyacrylate, polyacrylamide, and initial setting time, gelling time as well as inorganic polymer blend viscosity, when base material and coagulant ratios were 2:3, 2:4 and 2:5, respectively. As shown in the tables, the larger the mass fraction of polymer, the greater the viscosity, the shorter the initial setting time and the gelling time. The measured inorganic gel viscosity was $1.13 \mathrm{mPa} \bullet$ s. Under certain mass ratio of base material and coagulant, viscosity of polymer added with gel was greater than inorganic gel, but initial setting time and gelling time of polymer added with gel was less than inorganic gel. The initial setting time and gelling time of polyacrylamide added gel was shorter than sodium polyacrylate added gel. Under the same mass fraction of cases, the viscosity of polyacrylamide added gel was greater than sodium polyacrylate added gel. However, the process of dissolution of polyacrylamide was easy to agglomerate, and the greater the viscosity of the flow, the greater the resistance and adverse perfusion, so it was an appropriate consideration that chose sodium polyacrylate.

Best proportion of yellow mud adding gel composite materials. On the basis of the gel material selection, the main factors those affect the gelling time of yellow mud added gel were studied by orthogonal experiments. Table 5 shows the levels of influence factors and other factors. Using $\mathrm{L}_{9}\left(3^{4}\right)$ orthogonal experimental table arranging experiment, its gelling time was measured. The experimental arrangement and the final result are shown in table 6.

Table 5 Affecting factors and their levels

\begin{tabular}{c|c|c|c|c}
\hline Factor & $\begin{array}{c}\text { Soil and water } \\
\text { ratio(A) }\end{array}$ & $\begin{array}{c}\text { Base material } \\
\text { dosage (\%) B }\end{array}$ & $\begin{array}{c}\text { Coagulant dosage } \\
(\%) \mathrm{C}\end{array}$ & $\begin{array}{c}\text { Polymer dosage } \\
(\%) ~ D\end{array}$ \\
\hline 1 & $3: 1$ & 2 & 3 & 0.5 \\
\hline 2 & $4: 1$ & 3 & 4 & 0.75 \\
\hline 3 & $5: 1$ & 4 & 5 & 1 \\
\hline
\end{tabular}

Table 7 and Fig.6 show the analysis results of range analysis method. Comparison of range value, $\mathrm{C}>\mathrm{B}>\mathrm{D}>\mathrm{A}$, namely the orders of factors affecting gelling time is: $\mathrm{C}-\mathrm{B}-\mathrm{D}-\mathrm{A}$.

Table 6 Proportion arrangement and experimental results

\begin{tabular}{|c|c|c|c|c|c|c|}
\hline \multirow{2}{*}{ Test number } & \multicolumn{4}{|c|}{ Factor } & \multirow{2}{*}{ Test scheme } & \multirow{2}{*}{ Gelling time ( $\mathrm{min})$} \\
\hline & $\mathrm{A}$ & $\mathrm{B}$ & $\mathrm{C}$ & $\mathrm{D}$ & & \\
\hline 1 & 1 & 1 & 1 & 1 & $\mathrm{~A}_{1} \mathrm{~B}_{1} \mathrm{C}_{1} \mathrm{D}_{1}$ & 28.36 \\
\hline 2 & 1 & 2 & 2 & 2 & $\mathrm{~A}_{1} \mathrm{~B}_{2} \mathrm{C}_{2} \mathrm{D}_{2}$ & 7.5 \\
\hline 3 & 1 & 3 & 3 & 3 & $\mathrm{~A}_{1} \mathrm{~B}_{3} \mathrm{C}_{3} \mathrm{D}_{3}$ & 2.75 \\
\hline 4 & 2 & 1 & 2 & 3 & $\mathrm{~A}_{2} \mathrm{~B}_{1} \mathrm{C}_{2} \mathrm{D}_{3}$ & 15.57 \\
\hline 5 & 2 & 2 & 3 & 1 & $\mathrm{~A}_{2} \mathrm{~B}_{2} \mathrm{C}_{3} \mathrm{D}_{1}$ & 7.4 \\
\hline 6 & 2 & 3 & 1 & 2 & $\mathrm{~A}_{2} \mathrm{~B}_{3} \mathrm{C}_{1} \mathrm{D}_{2}$ & 6.3 \\
\hline 7 & 3 & 1 & 3 & 2 & $\mathrm{~A}_{3} \mathrm{~B}_{1} \mathrm{C}_{3} \mathrm{D}_{2}$ & 8.62 \\
\hline 8 & 3 & 2 & 1 & 3 & $\mathrm{~A}_{3} \mathrm{~B}_{2} \mathrm{C}_{1} \mathrm{D}_{3}$ & 46.62 \\
\hline 9 & 3 & 3 & 2 & 1 & $\mathrm{~A}_{3} \mathrm{~B}_{3} \mathrm{C}_{2} \mathrm{D}_{1}$ & 6.03 \\
\hline
\end{tabular}


Table 7 Results of range analysis

\begin{tabular}{cc|c|c|c|c}
\hline \multicolumn{2}{r|}{ Factor } & A & B & C & D \\
\hline $\mathrm{K}_{1}$ & 12.843 & 17.490 & 27.067 & 13.903 \\
\hline $\mathrm{K}_{2}$ & 9.758 & 20.507 & 9.700 & 7.473 \\
\hline $\mathrm{K}_{3}$ & 20.423 & 5.027 & 6.257 & 21.647 \\
\hline $\mathrm{R}$ & 10.666 & 15.480 & 28.810 & 14.174 \\
\hline
\end{tabular}

Coagulant dosage has the biggest effect on gelling time, and the larger the coagulant dosage, the shorter the gelling time. It has the biggest effect on gelling time when coagulant dosage is $3 \% \sim 5 \%$. When coagulant dosage is more than $5 \%$, the changing impact on gelling time is decreased. Gelling time decreases with the increase of the base material dosage, and the base material dosage is $2 \%$ $4 \%$ when it has the biggest effect on gelling time. When base material usage is more than $4 \%$, the changing impact on gelling time is deceased. The effect on gelling time is not obvious, when water-to-soil ratio is in 1:3 to 1:5.

In order to ensure covering effect of yellow mud adding gel material filled into the coal, and meet the conditions of gelling time and viscosity, the optimal proportion is that: water-to-soil ratio is $4: 1$, base material dosage is $4 \%$, coagulant dosage is $5 \%$, and polymer dosage is $0.75 \%$.

\section{Conclusions}

(1) Composite gel is injected into the body of coal, wetting and forming a layer of insoluble membrane, reducing the surface oxygen concentration, and increasing the cooling area. By increasing the thermal conductivity and specific heat capacity, exothermic heat is reduced and heat emission is increased, thus preventing spontaneous combustion of coal.

(2) When water-to-soil ratio and the base material dosage are certain, the relations between coagulant dosage and the gelling time comply with the regression equation $t=a_{B}{ }^{-b}$.

(3) Viscosity and gelling time of the gel can be changed, by adding polymer materials into inorganic gel. The greater the polymer mass fraction, the greater the viscosity, the shorter the gelling time.

(4) Best proportion of yellow mud adding gel composite is determined as follows: water soil ratio is $4: 1$, base material dosage is $4 \%$, coagulant dosage is $5 \%$, and polymer dosage is $0.75 \%$. The water content is $>80 \%$, and the adjustable of gelling time is $1 \sim 30 \mathrm{~min}$.

\section{References}

[1] Zhu H.Q., Liu X.K., Theoretical study of top coal spontaneous combustion hazard analysis and injecting nitrogen for fire prevention, J. China Coal Soc. 37(6) (2012) 1015-1020.

[2] Gouws R., Van Jaarsveldt H., Thermal and efficiency analysis of a single phase induction motor with Peltier devices, World J. Eng. 9(1) (2012) 63-70.

[3] Zubíček V, Adamus A. , Susceptibility of coal to spontaneous combustion verified by modified adiabatic method under conditions of Ostrava-Karvina Coalfield, Czech Republic, Fuel Process Technol. 113 (2013) 63-66.

[4] Xiao H. F., Tian Y. L. , Prediction of mine coal layer spontaneous combustion danger based on genetic algorithm and BP neural networks, Procedia Eng. 26 (2011) 139-146.

[5] Yang X.M. , Research on coal spontaneous combustion fire disaster management technology in mined-out area traversed by roadway. Xi'an: Xi'an Univ. Sci. Technol. (2012).

[6] Yan R.L. , Qian G.Y. , The molecular structure and gas coal spontaneous combustion of coal, J. China Coal Soc. (S1) ( 1995) 58-64. 
[7] Xu J.C., Xue H.L. ,Wen H, et al. Analysis on influential factors of thermal effect in coal oxidation, J. of Saf. Sci. Technol. 11(2) (2001) 31-36.

[8] Jiao Y., Duan Y.L., Zhou X .Q., et al., The law of methane explosion induced by spontaneous combustion process in closed fire zone of coal mines, J. China Coal Soc. 37 (5) (2012) 850-856.

[9] Li Yinghua, Zhang Renwei, Dai X iaoliang, et al, Research on the yellow mud grouting fire-fighting system in Bei Xin Yao coal mine, Energy Technol. Manage. (4) (2011), 63-65.

[10] Meng J.H., Tong X.L., Fire extinguishing technology transformation of anti-yellow mud grouting, Sci. Technol. Information (2) (2013) 508. 